\title{
Distancia de las raíces de primeros y segundos molares superiores con el seno maxilar, mediante Tomografía Computarizada Cone Beam.
}

\section{Distance of the roots of the first and second upper molars with the maxillary sinus, using Cone Beam Computed Tomography.}

\author{
María Karina Pinos Luzuriaga1 $^{1 *}$, Alberto Leoncio Alvarado Cordero ${ }^{2}$ Cristina Sibri Quizhpe $^{3}$ Cristina Torres \\ Maldonado ${ }^{4}$ \\ ${ }^{1}$ Odontóloga Especialista en Endodoncia. Práctica privada. Cuenca, Ecuador. \\ ${ }^{2}$ Docente de la Universidad Católica de Cuenca, Especialista en Ortodoncia. Cuenca, Ecuador. \\ ${ }^{3}$ Odontóloga rural del Ministerio de Salud Pública, Ecuador. \\ ${ }^{4}$ Odontóloga rural del Ministerio de Salud Pública, Ecuador. \\ *karyp108@gmail.com
}

\begin{abstract}
Resumen
Intervenciones dentales como la cirugía y endodoncia a nivel de los molares superiores conlleva un riesgo por su proximidad con el seno maxilar. La probabilidad de esta eventualidad varía dependiendo de la raíz (palatina, mesiovestibular o distovestibular), y de sus variaciones anatómicas e individuales ligadas al sexo, edad y mezcla racial. Los inconvenientes producidos durante dichos procedimientos odontológicos que sobrepasan o alteran esta proximidad anatómica pueden acarrear complicaciones como son sinusitis odontogénica y comunicación oro-antral. Objetivo: Determinar la distancia que existe entre los ápices de los primeros y segundos molares maxilares y el seno maxilar a través de imágenes de CBTC. Metodología: Se realizó un estudio de 76 imágenes que fueron realizadas con tomografía "ConeBeam" en pacientes de entre 14 a 60 años de edad, los cuales fueron recogidos de una base de datos aleatoria del servicio de radiología de la Carrera de Odontología de la Universidad Católica de Cuenca. Conclusiones: En el presente estudio se encontró que la raíz mesiovestibular del primer molar superior, seguido de la raíz distovestibular del segundo molar superior izquierdo, siendo la primera la que presentó un porcentaje más alto.
\end{abstract}

Palabras clave: Raíz del diente, ápice radicular, seno maxilar, tomografía.

Treatment at the level of the upper molars carries a risk due to their proximity to the maxillary sinus. The probability of this risk varies according to whether the root is palatine, mesiovestibular or dystovestibular and also to the variations of each individual linked to sex, age and racial mixture. Treatments at this level can lead to complications such as odontogenic sinusitis and oro-anthral communication. Objective: To determine the distance between the apexes of the first and second maxillary molars and the maxillary sinus through CBTC images. Methodology: A study of 76 images was performed with "Cone Beam" tomography in patients between 14 and 60 years of age, which were collected from a random database of the radiology service of the Career of Dentistry of the Catholic University of Cuenca. Conclusions:In the present study it was found that the mesiovestibular root of the first, second right molar, first left molar has a greater relationship with the maxillary sinus followed by the dystovestibular root of the second upper left molar, being the first one the one that presented a higher percentage.

Key words: Tooth root, maxillary sinus, tomography.

\section{INTRODUCCIÓN}

La tomografía "Cone Beam “, CBCT (ConeBeanComputedTomography), inicia como opción imagenológica, por la necesidad de obtener mayor precisión en los diagnósticos y tratamientos dentales. Este estudio tiende a reemplazar a la imagen panorámica, oclusal y periapical, presentando las ventajas de evitar distorsión por sobre posición de estructuras anatómicas, referencia exacta de estructuras adyacentes y una escala de 1:1, permitiéndonos una planificación adecuada para tratamientos dentales como cirugía, colocación de 
implantes y endodoncia. ${ }^{1}$

Los molares maxilares son piezas dentales que son sometidas muy frecuentemente a intervenciones dentales, por lo cual es importante conocer que los ápices de sus raíces guardan una estrecha relación con el seno maxilar, siendo separados únicamente con una membrana muy fina de 5-8 mm conocida como membrana de Scheiner, la cual puede ser injuriada durante tratamientos dentales clínicos o quirúrgicos, generando una comunicación oro-antral y/o sinusitis odontogénica. ${ }^{2,3}$

Por lo tanto CBCT nos permite la correcta identificación de la anatomía de los senos nasales y conocer la distancia que existe con los ápices de molares maxilares. ${ }^{1-3}$

El objetivo de este estudio fue determinar la distancia que existe entre los ápices de los primeros y segundos molares maxilares y el seno maxilar a través de imágenes de CBTC. Estos resultados nos permitirán obtener información relacionada con nuestro entorno en relación con las variantes anatómicas, para prevenir iatrogenias durante los procedimientos odontológicos citados anteriormente.

\section{MATERIAL Y MÉTODOS}

Se realizó un estudio retrospectivo y lineal que incluyo 76 imágenes CBCT de pacientes hombres y mujeres entre 14 a 60 años de edad. La selección de la muestra fue aleatoria por medio de una base de datos del servicio de radiología de la Carrera de Odontología de la Universidad Católica de Cuenca, ceñida estrictamente a los criterios de inclusión y exclusión establecidos. Los criterios de inclusión fueron imágenes tomográficas maxilares de pacientes de 14 a 60 años de ambos sexos. Los criterios de exclusión de la muestra del estudio fueron imágenes tomográficas maxilares con ausencia de molares maxilares o molares, patologías periapicales y reabsorciones radiculares. En la estación de trabajo se editaron las imágenes tomografícas, mediante el Software Skyviewa.A, su vez se obtuvieron diferentes imágenes por medio de cortes tomográficos. Utilizando la dosis de 43,2 a $58 \mathrm{mSv}$ (microsieverts) con un tiempo de exposición de 10.5 a 15,8 segundos, se almacenaron en formato DICOM en un computador HP con pantalla de 16 pulgadas y resolución de 1280 x 800 pixeles; además se utilizaron programas como: OpenEpi, Excel y SPSS22.0,

\subsection{Mediciones tomográficas}

Se editaron las imágenes tomográficas utilizando el software i Dixel del equipo 3D Accuitomo 170 MORITA, sistema DICOM el cual nos brinda diferentes cortes tomográficos a través de monitor con pantalla de cristal. Los puntos de estudio fueron examinados en planos anatómicos para sagital, proporcionando imagen del ápice de las raíces $\mathrm{P}$, y MV y DV primer molar superior y la raiz $\mathrm{P}, \mathrm{MV}$ y DV del segundo molar superiores respectivamente. Las mediciones se realizaron tomando dos puntos de referencia inicial y final, el punto inicial fue el ápice tomográfico y el final fue el piso del seno maxilar. Las mediciones que se extendían sobre el piso del seno maxilar fueron asignadas con valores negativos y como muestras de riesgo, mientras los que se ubicaban por debajo del seno maxilar fueron asignados con valores positivos y como muestras sin riesgo.. Dos investigadores cursaron por una calibración intra e interoperador previo al levantamiento de la muestra, con la guía de un radiólogo Buco Maxilo Facial con experiencia en CBCT.

\section{RESULTADOS}

\subsection{Raíz MV 16. (Primer molar superior derecho)}

Los resultados de la de la raíz MV16 sin riesgo fueron de $60,5 \%(n=46)$, y con riesgo en relación al seno maxilar de $39,5 \%(n=30)$, con una distancia media en milímetros de $0,26 \mathrm{~mm}(2,48)$. La prevalencia de raíces sin riesgo predominó en el sexo femenino con un 34,2\% ( $\mathrm{n}=26)$, a diferencia de $26,3 \%(n=20)$ en el masculino. En cuanto a las raíces con riesgo en los hombres se obtuvo un $21 \%(n=16)$ sobre el sexo femenino con un $18,5 \%(n=14)$, con un $(p<0,40)$, sin existir diferencias significativas. Los resultados según edad, el grupo etario más prevalente, fue de 11 a 17 años con 18,4\% $(n=14)$ en raíces sin riesgo, a diferencia de las que las raíces sin riesgo con un $10,5 \%(n=8)$. Sin presentar diferencias significativas con un valor $(\mathrm{p}<0,92)$.

\subsection{Raíz DV 16. (Primer molar superior derecho)}

La prevalencia sin riesgo en la raíz DV16 fue de 67,1\% $(n=51)$, difiriendo de las raíces con riesgo con un $32,9 \%$ $(\mathrm{n}=25)$, con una media de $0,49 \mathrm{~mm}(2,20)$. Las raíces sin riesgo arrojaron una prevalencia de $38,1 \%(\mathrm{n}=29)$ en el sexo femenino sobre el sexo masculino con un $29 \%(n=22)$. A diferencia de las raíces con riesgo siendo el sexo masculino el más prevalente con un 18,4\% $(n=14)$ en relación al sexo femenino con un $14,5 \%(n=11)$. Sin significancia con $(p<0,29)$. El grupo etario de 11 a 17 años, resultó ser el más prevalente siendo las raíces sin riesgo con $17,1 \%(\mathrm{n}=13)$ superando a las raíces con riesgo con un $11,8 \%(n=9)$. Con un $(p<0,59)$ sin significancia.

\subsection{Raíz P16. (Primer molar superior derecho)}

Los resultados sin riesgo de la raíz P16 fueron de $75 \%$, $(\mathrm{n}=57)$, difiriendo de las raíces con riesgo con $25 \% \mathrm{n}=19$, con una media de $1.87 \mathrm{~mm}(3,47)$. En el sexo femenino las raíces sin riesgo tuvieron una prevalencia de 43,5\% $n=33$, sobre el sexo masculino con el $31,5 \% \mathrm{n}=24$. En cuanto a las raíces con riesgo el sexo masculino fue más prevalente con $16 \% \mathrm{n}=12$, en relación al sexo femenino con $9 \% \mathrm{n}=7$. Sin significancia con $(\mathrm{p}<0,11)$. En cuanto a la edad el grupo 
más prevalente fue de 11 a 17 años con $25 \%$ n=16 en las raíces sin riesgo, y $8 \% \mathrm{n}=6$ en las raíces con riesgo. Sin una significancia de $(\mathrm{p}<0,10)$.

\subsection{Raíz MV17. (Segundo molar superior derecho)}

Los resultados de la raíz MV17 muestran una prevalencia de raíces sin riesgo de 56,6\% (n=43), A diferencia de las raíces con riesgo 43,4\% (n=33); con una distancia media en milímetros de $0,49 \mathrm{~mm}(2,69)$. El sexo femenino presentó mayor porcentaje de raíces sin riesgo con un $31,6 \%$ en relación con el sexo masculino $25 \%$. El sexo masculino presento mayor raíces con riesgo con un $22,4 \%$, a diferencia del sexo femenino que obtuvo un $21 \%$. Sin presentar significancia con un valor $(\mathrm{p}<0,52)$. El grupo etario de 11 a 17 años de edad obtuvo un mayor porcentaje con un $29 \%$, de los cuales el $14.5 \%(n=11)$ fueron raíces con riesgo y $14,5 \%(n=11) \sin$ riesgo. Sin presentar significancia con un valor $(p<0,52)$.

\subsection{Raíz DV 17. (Segundo molar superior derecho)}

La prevalencia sin riesgo en la raíz DV17 fue de 64,5\% $(n=49)$, y con riesgo es 35,5\% ( $n=27)$, la distancia Media fue de $0,92 \mathrm{~mm}(2,74)$. Las raíces sin riesgo fueron más prevalentes en el sexo femenino con $32,9 \%(n=25)$ que en el sexo masculino con $31,6 \%(n=24)$. En el sexo femenino se obtuvo una prevalencia de $19,7 \%(n=15)$ en las raíces con riesgo, superando al sexo masculino con un porcentaje de $15,8 \%(n=12)$. Con un valor $(\mathrm{p}<0,70)$ sin significancia. Sin considerar el sexo como un variable predisponente en la cercanía de la raíz con el Seno Maxilar. De igual manera el grupo etario con mayor prevalencia es el de 11 a 17 años con un $29 \%(n=22)$, con raíces sin riesgo en un $18,4 \%(n=14)$ y con riesgo en un $10,5 \%(\mathrm{n}=8)$; con un valor $(\mathrm{p}<0,58)$, lo que quiere decir que no existe significancia.

\subsection{Raíz P17. (Segundo molar superior derecho)}

Los resultados de la raíz $\mathrm{P} 17$ sin riesgo en relación con el seno maxilar son de $65,8 \%(n=50)$ y con riesgo $(n=26)$ $34,2 \%$. Con una distancia Media de 1,54mm . La prevalencia de raíces sin riesgo fue mayor en el sexo femenino con un $36,8 \%(n=28)$ en relación con el sexo masculino que obtuvo un $28,9 \%(n=22)$. A diferencia que en las raíces con riesgo el mayor porcentaje fue mayor para el sexo masculino con un $18,14 \%(n=14)$ que en el sexo femenino que fue de $15,8 \%$ $(n=12)$. Con un valor $(p<0,4)$ lo cual indica que no existe significancia. En cuanto al grupo etario el más prevalente fue el de 11 a 17 años de edad, en donde se observó que las raíces sin riesgo fueron más prevalentes con un $21 \%(n=16)$ en relación con las raíces con riesgo $8 \%(n=6)$, no se obtuvo significancia debido a al valor $(\mathrm{p}<0,61)$.

\subsection{Raíz MV26. (Primer molar superior izquierdo)}

La prevalencia sin riesgo en la raíz MV16 fue de 71,1\% $\mathrm{n}=54$, a diferencia de las raíces con riesgo $28,9 \% \mathrm{n}=22$, con una media de $1,45 \mathrm{~mm}(3,02)$. La prevalencia de raíces $\sin$ riesgo predominó en el sexo femenino con un 38,1 \% ( $\mathrm{n}=29)$, a diferencia de 32,9\% $(n=25)$ en el masculino. En cuanto a las raíces con riesgo, la prevalencia en el sexo femenino y el sexo masculino fue la misma con un $14,5 \% \mathrm{n}=11$. Sin obtener significancia con un valor $(\mathrm{p}<0,76)$. De acuerdo a la edad predominó el grupo etario de 11 a 17 años con un $14,5 \%, \mathrm{n}=11$ en las raíces con riesgo y sin riesgo, Obteniendo un valor $(\mathrm{p}<0,02)$ con significancia.

\subsection{Raíz DV26. (Primer molar superior izquierdo)}

Los resultados sin riesgo de la raíz DV26 fueron de $75 \%, \mathrm{n}=57$, difiriendo de las raíces con riesgo con $25 \%$ $\mathrm{n}=19$, con una media de $1.91 \mathrm{~mm}$. En el sexo femenino las raíces sin riesgo tuvieron una mayor prevalencia de 39,5\% $\mathrm{n}=30$, sobre el sexo masculino con el $35,5 \% \mathrm{n}=27$. A diferencia de las raíces con riesgo el sexo femenino fue más prevalente con $13,2 \% \mathrm{n}=10$, en relación al sexo masculino con $11,8 \% \mathrm{n}=9$. Sin significancia con valor $(\mathrm{p}<1,00)$. En cuanto a la edad el grupo más prevalente fue de 11 a 17 años con $18,4 \% \mathrm{n}=14$ en las raíces sin riesgo, a diferencia de las raíces con riesgo $10,5 \% \mathrm{n}=8$, Sin una significancia de $(\mathrm{p}<0,12)$.

\subsection{Raíz P26. (Primer molar superior izquierdo)}

Los resultados de la raíz $\mathrm{P} 26$ sin riesgo en relación con el seno maxilar son de $72,4 \%(n=55)$ y con riesgo $27,6 \%$ $(n=21)$. Con una distancia media de $2,17 \mathrm{~mm}$. La prevalencia de raíces sin riesgo fue mayor en el sexo femenino con un $44,7 \%(n=34)$ en relación con el sexo masculino que obtuvo un $27,6 \%(n=21)$. A diferencia que en las raíces con riesgo el mayor porcentaje fue mayor para el sexo masculino con un $19,7 \%(n=15)$ que en el sexo femenino que fue de $7,9 \%$ $(n=6)$. Con un valor $(\mathrm{p}<0,009)$ lo cual indica que existe significancia. En relación al grupo etario el más prevalente fue el de 11 a 17 años de edad, en donde se obtuvo que las raíces sin riesgo fueron más prevalentes con un 21,1\% $(n=16)$ en relación con las raíces con riesgo 7,9\% $(n=6)$, no se obtuvo significancia debido a al valor $(\mathrm{p}<0,63)$.

\subsection{Raíz MV27. (Segundo molar superior izquierdo)}

La prevalencia sin riesgo en la raíz MV27 fue de 61,8\% $(n=47)$, y con riesgo es 38,2\% $(n=29)$, la distancia Media fue de $0,78 \mathrm{~mm}$. Las raíces sin riesgo fueron más prevalentes en el sexo femenino con $35,5 \%(n=27)$ que en el sexo masculino con $26,3 \%(n=20)$. En el sexo masculino se obtuvo una prevalencia predominante con un $21 \%(n=16)$ en las raíces con riesgo, superando al sexo femenino con un porcentaje de $17,1 \%(n=13)$. Con un valor $(p<0,28)$ sin significancia. En el cual no se considera el sexo como un variable predisponente en la cercanía de la raíz con el seno maxilar. De igual manera el grupo etaria con mayor prevalencia es el de 11 a 17 años con un $15,8 \%(\mathrm{n}=12)$, con raíces sin riesgo, en relación a 
las raíces con riesgo presentando un $13,1 \%(n=10)$ y con un valor $(\mathrm{p}<0,52)$, lo que quiere decir que no existe significancia en relación al Seno Maxilar.

\subsection{DV27. (Segundo molar superior izquierdo)}

La prevalencia sin riesgo fue mayor en la raíz DV27 fue de $59,2 \%(n=45)$, difiriendo de las raíces con riesgo con un $40,8 \%(\mathrm{n}=31)$, con una media de $1,35 \mathrm{~mm}(2,64)$. Las raíces sin riesgo arrojaron una prevalencia mayor en el sexo femenino de $31,6 \%(n=24)$ sobre el sexo masculino con un $27,6 \%(n=21)$. A diferencia de las raíces con riesgo siendo el sexo femenino también el más prevalente con un $21 \%$ $(n=16)$ en relación al sexo masculino con un 19,2\% $(n=15)$. Sin presentar significancia con un valor $(\mathrm{p}<0,88)$. En cuanto al grupo etario de 11 a 17 años, resultó ser el más prevalente siendo las raíces sin riesgo con $17,1 \%(n=13)$ superando a las raíces con riesgo con un $11,8 \%(\mathrm{n}=9)$. Con un $(\mathrm{p}<0,80)$ lo que indica que no existe una significancia.

\subsection{Raíz P27. (Segundo molar superior izquierdo)}

Los resultados de la raíz P27 sin riesgo en relación con el seno maxilar son de $76,3 \%(n=58)$ y con riesgo $23,7 \%(\mathrm{n}=18)$. Con una distancia media de $2,18 \mathrm{~mm}(3,38)$. La prevalencia de raíces sin riesgo fue mayor en el sexo femenino con un $40,8 \%(n=31)$ en relación con el sexo masculino que obtuvo un $35,5 \%(n=27)$. A diferencia de las raíces con riesgo las cuales presentan un porcentaje igual tanto en el sexo femenino como masculino $11,8 \%(n=9)$. Con un valor $(\mathrm{p}<0,79)$ lo cual indica que no existe significancia. En cuanto al grupo etario el más prevalente fue el de 11 a 17 años de edad, en donde se observó que las raíces sin riesgo fueron más prevalentes con un 19,7\% $(n=15)$ en relación con las raíces con riesgo $9,2 \%(n=7)$, No se obtuvo significancia debido al valor $(\mathrm{p}<0,22)$.

\section{DISCUSIÓN}

El presente estudio tuvo como objetivo conocer la distancia entre los ápice radiculares de los primeros y segundos molares superiores con el seno maxilar según el sexo y el grupo etario, mediante CTCB. Se obtuvo como resultado que la raíz mesio-vestibular del primer molar superior derecho e izquierdo fue la más cercana al seno maxilar con una distancia media en milímetros de 0,26 $\mathrm{mm}$. En relación con el sexo y la edad no hubo diferencias significativas, lo que difiere de los resultados obtenidos en la investigación de Durgesh Bailoor, en donde se concluyó que la raíz palatina fue la más cercana. ${ }^{4}$

La dimensión de la nasofaringe aumenta con la edad en el sexo masculino, no habiéndose encontrado relación en el sexo femenino ni en la dimensión de la orofaringe.A su vez la segunda raíz con mayor cercanía al seno maxilar fue la distovestibular del segundo molar superior derecho con una distancia media en milímetros de $0.49 \mathrm{~mm}$. En relación con el sexo y la edad no hubo diferencias significativas. Comparándola con un estudio de García et al de nuestro medio la distancia de esta raíz respeto al seno fue de $0.27 \mathrm{~mm}^{5}$

Es importante mencionar que en nuestra investigación en todos los ápices las raíces investigadas la mayoría están clasificadas dentro del grupo de raíces sin riesgo, es decir las que se encuentran fuera del seno son más prevalentes que las raíces dentro del seno son.

Cabe mencionar la importancia de obtener estos datos en nuestra población, debido a que las piezas dentales evaluadas son candidatas muy frecuentes en desarrollar patologías pulpares y periapicales que pueden llegar a conectar al seno maxilar, dicha estructura anatómica plantea un reto al profesional durante el diagnóstico, tratamiento y pronóstico de la endodoncia o cirugía endodóntica, principalmente a nivel de los dientes posterosuperiores, ya que pese a guardar todos los protocolos endodónticos esta área de trabajo es muy limitada visualmente. ${ }^{6}$

Entre las complicaciones más frecuentes que se pueden presentar durante y después de la terapia endodóntica por primera intención o por un retratamiento por errores de procedimiento, es el paso inadvertido de hipoclorito de sodio a los tejidos periapicales, pudiendo alcanzar el seno maxilar, provocando reacciones inflamatorias severas y tóxicas. ${ }^{6}$

Este accidente incluye, disnea, dolor severo, edema, hemorragia intersticial y dental, equimosis creciente con resolución completa después de algunas semanas, y en casos más graves puede presentar necrosis tisular, parestesia e infecciones secundarias. .,7 $^{6}$

Entre los casos reportados de inyección inadvertida de hipoclorito de sodio al seno maxilar durante la terapia endodóntica fue la de un primer molar superior derecho en relación con el conducto palatino sin consecuencias graves, ${ }^{3}$ y el segundo caso tuvo relación con un segundo premolar maxilar derecho, terminando por la extracción de dicha pieza por su sintomatología dolorosa persistente. ${ }^{6}$

Pese a que no existen reportes de accidentes de hipoclorito de sodio en relación con los dientes con raíces de riego más prevalentes en esta investigación, es de mucha importancia tener en cuenta para evitar posibles complicaciones inherentes con las características anatómicas de nuestro medio. A su vez se pueden mencionar otras complicaciones como la introducción de instrumentoso materiales de obturación que pueden actuar como cuerpos extraños generando citotoxicidad, inflamación crónica, alteración del epitelio respiratorio, infección por hongos 
los cuales pueden permanecer asintomáticos durante varios años. ${ }^{8,9}$

Dentro de los reportes se mencionan dos casos de penetración de conos de gutapercha al seno maxilar a través de la raíz palatina de primeros molares superiores 13 , y un reporte en relación con un segundo molar superior derecho desencadenando una infección por Escherichiacoli a nivel del seno maxilar. ${ }^{10}$

También se mencionan respuestas inflamatorias después de la preparación de los conductos por liberación de mediadores de inflamación hacia la mucosa del seno o la extrucción de tejido durante la instrumentación de los conductos de diente posterosuperiores pese a mantener una longitud de trabajo exacta. ${ }^{11,12}$

La cirugía endodontica está indicada únicamente en los casos que no se pueden resolver o inhibir la patología preexistente por vía retrograda o en aquellos casos refractarios. Su intervención debe ser muy meticulosa, complementada indispensablemente de imágenes tomográficas y radiográficas, aun así existe alto riego de perforar la mucosa durante la apicectomia, permitiendo inclusive el paso del fragmento dental al seno maxilar, lo que involucra una complicación quirúrgica importante. ${ }^{6}$

Freedman y Horowitz estimó que la perforación del seno durante una cirugía apical es del $23 \%$ para los molares. En un estudio de 200 raíces superiores Rud y Rud estimó que en el $50 \%$ de los casos se produjo una comunicación endoantral. ${ }^{13}$

Sin embargo, a todas las posibles complicaciones antes mencionadas, la invasión del seno maxilar no parece resultar en una alteración permanente, observando que la mucosa de la membrana se puede regenerar a los cinco meses después de retirar el agente extraño y restablecer la ventilación decuada. ${ }^{14}$

Es necesario tener un buen conocimiento de la anatomía interna del complejo sistema de conductos radiculares y su relación con otras entidades anatómicas cercanas, un diagnóstico correcto y procedimiento de técnicas adecuados. $^{11}$

\section{Conclusiones}

En los molares superiores hemos encontrado que en promedio de todas las raíces el 32,88\% tienen riesgo de presentar complicaciones relacionadas al seno maxilar, , 10 por lo cual es realmente importante tomar en cuenta este riesgo como medida preventiva en el tratamiento evitando 1 una sinusitis transitoria por generación de sangre en el seno maxilar y fistula oro-antral.

Existen ligeras diferencias en relación al sexo entre unas raíces y otras, aunque hubo diferencias en cuanto a la edad del paciente es importante recordar que a mayor edad hay un aumento del desarrollo del seno maxilar y mayor riesgo por la neumatización.

Por lo tanto es de vital importancia un buen conocimiento de la anatomía interna del complejo sistema de conductos radiculares y su relación con otras entidades anatómicas cercanas, un diagnóstico correcto y procedimiento de técnicas adecuados.

\section{Referencias Bibliográficas}

1 Finlayson AF, et al. La tomografía computarizada de haz cónico. Ustasalud 2008; 7: 125-131.

2 Pinares J, et al. Variabilidad anatómica de los senos maxilares y de estructuras involucrdas en su vida de drenaje. AvancesenOdontoestomatología. Vol. 28 (2). 2012.

3 Eberhardt J, Tarabinejad M, Christiansen E. A computed tomographic study of the distances between the maxillary sinus floor and the apices of the maxillary posterior teeth. Oral Surg Oral Med Oral Pathol Oral RadioloEndod.1992; 73: 345.73: 345.1992.

4 Bailoor D, Handa H, Raghuvanshi V, Shrivstava K. Evaluation of Relationship of Root to Sinus in Maxillary Sinusitis PatientsA Comparative Assessment of Conventional Radiographs and CBCT. Journal of Advanced Medical and Dental Sciences Research. 2014 April-June; 2(2): p. 197-204

5 García SO. Cirugpia Oral; Seno maxilar; Relación senoraíz; Premolares; molares. [Trabajo de titulación] Guayaquil (Gye).Universidad Católica de Santiago de Guayaquil.2017. $28 \mathrm{p}$.

6 Hauman C, Chandler N, Tong D. Endodonticimplications of themaxillarysinus: a review. International Endodontic Journal.2002; 35, 127-141.

7 Kavanagh C, Taylor J. Inadvertent injection of sodium hypochlorite into the maxillary sinus. British Dental Journal.1998; 7, 336-7.

8 Mensi M, Piccioni M, Marsili F, et al. Risk of maxillary fungus ball in patients with endodontic treatment on maxillary teeth: a case-control study. Oral Surg Oral Med Oral Pathol Oral Radiol Endod.2007; 103:433-6.

9 Batur Y, Ersev H. Five-year follow-up of a root canal filling material in the maxillary sinus: a case report. Oral Surg Oral Med Oral Pathol Oral RadiolEndod 2008;106: e54-6.

10 Cazar M, Villasana J. Infección del seno maxilar por escherichiacoli: Revisión de la literatura y reporte de caso. 2015.

11 Seltzer S. Endodontology, 2nd edn. Philadelphia, USA: Lea and Febiger. 1988; 246, 316. 
12 Fairbourn D, McWalker G, Montgomery S. The effect of four preparation techniques on the amount of apically extruded debris. Journal of Endodontics.1987; 13, 102-8.

13 Rud J, Rud V. Surgical endodontics of upper molars: relation to the maxillary sinus and operation in acute state of infection. J Endod. 1998;24:260-261.

14 Selden H.The interrelationship between the maxillary sinus and endodontics. Oral Surgery Oral Medicine Oral Pathology.1974; 623-7.

Recibido: 05 de enero del 2020

Aceptado: 12 de abril del 2020 